
IP Periodica Polytechnica
Civil Engineering

\author{
62(1), pp. 206-218, 2018 \\ https://doi.org/10.3311/PPci.10647 \\ Creative Commons Attribution (i)
}

RESEARCH ARTICLE

\section{Study on Flexural Properties of Reinforced Spontaneous Combustion Gangue Concrete Beams}

\author{
Gaonian $\mathrm{Li}^{1}$, Baomin Wang ${ }^{1}$, Mei Zhou ${ }^{2}$
}

Received 18 February 2017; Revised 18 June 2017; Accepted 30 June 2017

\begin{abstract}
In this paper, the flexural properties of three kinds of reinforced spontaneous combustion gangue concrete (RSCG) beams and one group of reinforced normal concrete (RNC) beam are investigated experimentally by comparison. Three kinds of RSCG beams are constructed with 100\% spontaneous combustion gangue fine aggregate, coarse aggregate or both of them and one group conventional concrete beam is constructed with natural aggregates. Effects of different combinations of aggregates on flexural properties of reinforced concrete structural elements are studied under the same conditions, including longitudinal reinforcement ratio, concrete strength grade and section size of member. The experimental cracking moment, ultimate moment and deflection under normal service state of the beams are analyzed according to theories and methods of the present code to evaluate the applicability of present code for RSCG beams. In addition, through ANSYS finite element simulation, flexural properties of the RSCG beams are analyzed. And comparing experimental results with calculated and simulated results, respectively. The results show that flexural features of RSCG beams are similar with RNC beams, and flexural property formulas for conventional concrete beams are also suitable for RSCG beams. Furthermore, simulating results also agree well with test results. It is feasible to use spontaneous combustion gangue aggregate in reinforced concrete structures under the proper design as well as within the proper limit of application.
\end{abstract}

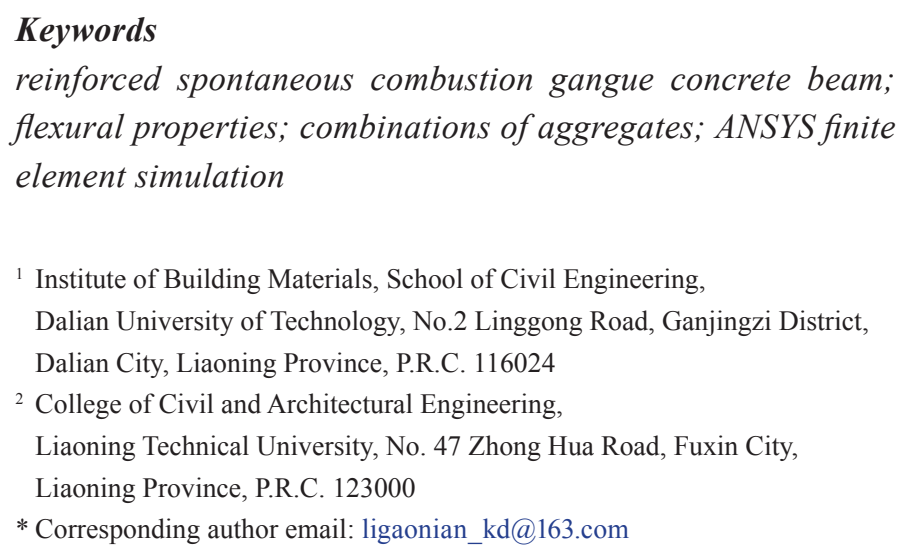

*Corresponding author email: ligaonian_kd@163.com

\section{Introduction}

Coal gangue is one of the largest solid wastes for mining enterprises. It is discharged when coal is exploited and washed in the production course. The accumulative stockpile of coal gangue has reached 3.8 billion metric tons and it is estimated that over 200 million metric tonnes of this waste is impounded annually in China [1]. A large number of simple piles of coal gangue take up lots of land. Mass storage of gangue can happen to spontaneously combust during long periods of exposure, meanwhile discharging $\mathrm{SO}_{2}, \mathrm{H}_{2} \mathrm{~S}, \mathrm{CO}, \mathrm{CO}_{2}, \mathrm{NO}_{\mathrm{X}}$ and heavy metal contamination [2], it is called "spontaneous combustion gangue" after that. All of above affect environment negatively. With the mass production of coal gangue, comprehensive utilization problem of gangue has been concerned in major coalproducing countries. In the west, some developed countries firstly carried on comprehensive utilization of gangue, until the late 1960s, wide attention was caused all over the world [3]. Some studies have shown that spontaneous combustion gangue can be utilized in concrete as aggregates [4-12], only needing to crush and screen. Aggregates take up about 70\% volume of concrete, compared to other ways to apply spontaneous combustion gangue, it is reasonable, efficient and green way for gangue utilization in building materials field, and its economic and environmental benefits are also quite remarkable. Consequently, utilization of gangue in building materials not only solves various types of environmental problems caused by large accumulation of gangue, but also compensates for the lack of natural aggregates.

However, properties of spontaneous combustion gangue aggregates are more complex than natural aggregates, because of its diversity of chemical constituents, complexity of mineral composition, uncertainty of storing time and so on. People often worry about their quality when using for structural materials. Moreover, some researchers [13] have tested the rock strength of spontaneous combustion gangue, they found that the strength of spontaneous combustion gangue is lower than natural stone. Thus the properties of itself and concrete made of gangue aggregates have caused much attention. Zhou et al. [14] and Zhang et al. [15] investigated the mechanical properties of 


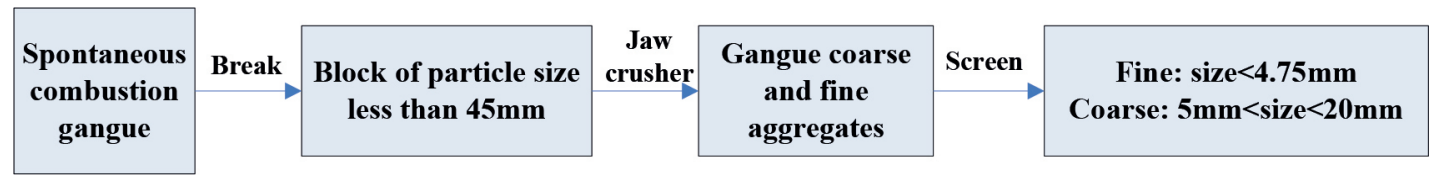

Fig. 1 Spontaneous combustion gangue aggregate production flow chart
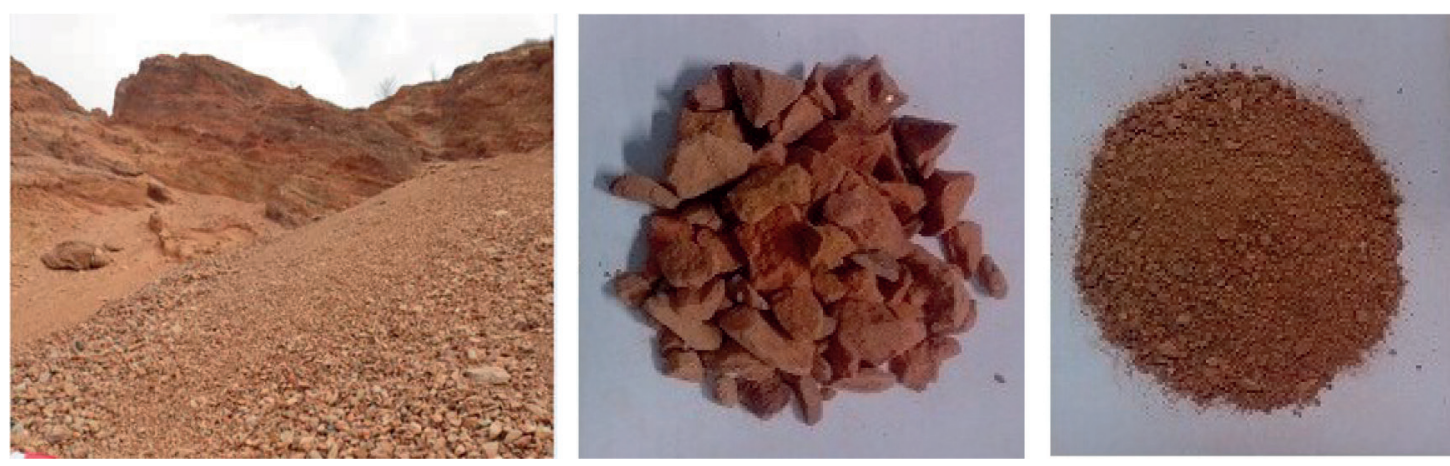

Fig. 2 The mountain, coarse and fine aggregates of spontaneous combustion gangue

Table 1 The main technical properties of aggregates

\begin{tabular}{|c|c|c|c|c|c|c|c|}
\hline \multirow[t]{2}{*}{ Category } & \multirow[t]{2}{*}{ Particle size } & \multicolumn{3}{|c|}{ Density $/ \mathrm{kg} / \mathrm{m}^{3}$} & \multirow[t]{2}{*}{ Water absorption $/ \%$} & \multirow[t]{2}{*}{ Crushing index $/ \%$} & \multirow[t]{2}{*}{ Fineness modulu } \\
\hline & & Apparent & Loose & Compact & & & \\
\hline SCG-fine & $<5 \mathrm{~mm}$ & 2433 & 1130 & 1185 & 12.43 & -- & 2.44 \\
\hline Natural sand & $<5 \mathrm{~mm}$ & 2580 & 1310 & 1430 & 3.17 & -- & 2.80 \\
\hline SCG-coarse & $5 \sim 20 \mathrm{~mm}$ & 2580 & 1092 & 1134 & 8.79 & 18.63 & -- \\
\hline Natural gravel & $5 \sim 20 \mathrm{~mm}$ & 2830 & 1560 & 1670 & 1.43 & 8.05 & -- \\
\hline
\end{tabular}

Note: SCG-fine represents spontaneous combustion gangue fine aggregate; SCG-coarse represents spontaneous combustion gangue coarse aggregate.

gangue as coarse aggregate. Moreover, Zhou et al. [16] studied the feasibility that spontaneous combustion gangue as an activated material is used in cement production, and the cement mixes with spontaneous combustion gangue coarse and fine aggregates to prepare concrete with different strength grade. You et al. [17] measured the durability parameters of spontaneous combustion gangue in Fuxin, China (The coal gangue used in this study is gathered from the same place), simultaneously, researched the current situations of spontaneous combustion gangue prefabricated concrete components. The results showed that the durability index of spontaneous combustion gangue met the corresponding requirements and durability of prefabricated components was good. However, Chen et al. [18] found the chloride ion permeability coefficient increased with the improvement of replacement ratio. It is due to the fact that spontaneous combustion gangue from different places has great differences. So we should test the properties of spontaneous combustion gangue fully and carefully. Previous studies focused on the material properties of the produce made of spontaneous combustion gangue. But there is few research on structure members made of spontaneous combustion gangue. Chen [19] only investigated the bearing capacity of flexural member made of gangue concrete. Li et al. [20-22] investigated the properties of gangue concrete filled steel tube members, the role of concrete, however, was weakened. And those studies were not sufficient for understanding behaviors of structural members so as to establish design methods. The aim of this paper is to investigate the applicability of spontaneous combustion gangue aggregate as a structural aggregate by comparing the flexural properties of three kinds of RSCG members (including reinforced spontaneous combustion gangue fine aggregate concrete (RSCG-F) beams, reinforced spontaneous combustion gangue coarse aggregate concrete (RSCG-C) beams and reinforced spontaneous combustion gangue coarse and fine aggregates concrete (RSCG-CF) beams) produced from spontaneous combustion gangue aggregate concrete with that of normal reinforced concrete members.

\section{Experimental}

\subsection{Raw materials}

Ordinary Portland cement (P.O42.5) is used in the test, with compressive strength of $49.51 \mathrm{MPa}$, flexural strength of $8.89 \mathrm{MPa}$ at the age of 28 days. Spontaneous combustion gangue is taken from the mine in Fuxin (Liaoning Province, China), detailed preparation process of spontaneous combustion gangue coarse and fine aggregates is showed in Fig.1. Furthermore, the mountain of spontaneous combustion gangue and coarse, fine aggregates of it can be seen in Fig.2. Some properties of aggregates are showed in Table 1. The grading of spontaneous combustion gangue fine or coarse aggregate is good. Polycarboxylate superplasticizer is employed to maintain the properties of fresh gangue concrete. Fly ash and slag mainly improve the workability of fresh concrete. 
Table 2 Mix proportion of C30 concrete $/ \mathrm{kg} / \mathrm{m}^{3}$

\begin{tabular}{|c|c|c|c|c|c|c|c|c|c|c|}
\hline Group & Cement & Fly ash & Slag & $\begin{array}{c}\text { Mixing } \\
\text { water }\end{array}$ & $\begin{array}{c}\text { Additional } \\
\text { water }\end{array}$ & $\begin{array}{l}\text { Water } \\
\text { reducer }\end{array}$ & SCG-fine & $\begin{array}{c}\text { Natural } \\
\text { sand }\end{array}$ & $\begin{array}{c}\text { Natural } \\
\text { gravel }\end{array}$ & SCG-coarse \\
\hline $\mathrm{NC}$ & 248 & 77 & 110 & 163 & 0 & 10 & 0 & 782 & 1036 & 0 \\
\hline SCG-F & 319 & 91 & 46 & 173 & 83 & 11 & 671 & 0 & 1095 & 0 \\
\hline SCG-C & 347 & 99 & 49 & 184 & 70 & 12 & 0 & 670 & 0 & 1005 \\
\hline SCG-CF & 368 & 105 & 53 & 189 & $76 / 69$ & 13 & 612 & 0 & 0 & 999 \\
\hline
\end{tabular}

Note: NC represents normal concrete prepared by natural sand and gravel; SCG-F represents the concrete made of spontaneous combustion gangue fine aggregate and natural gravel; SCG-C represents the concrete made of spontaneous combustion gangue coarse aggregate and natural sand; SCG-CF represents the concrete made of spontaneous combustion gangue fine and coarse aggregates (quantity of additional water $=$ quantity of aggregate $\times$ water absorption $\times$ a ratio $(100 \%$ for SCG-fine aggregate/ $80 \%$ for SCG-coarse aggregate)).

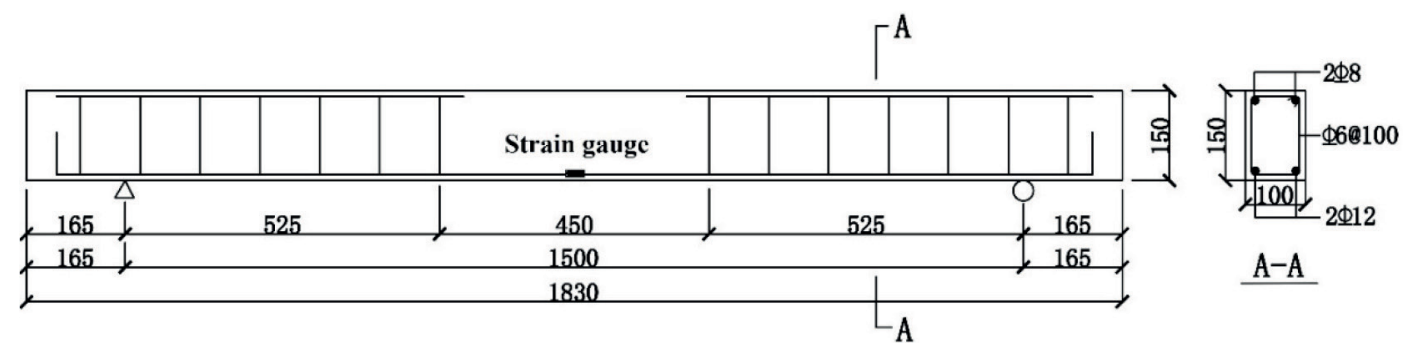

Fig. 3 Details of test beams (unit: $\mathrm{mm}$ )

\subsection{Experimental design}

\subsubsection{Mix proportion design}

In this test, the designing strength grade, C30, is widely used in general structure engineering. Spontaneous combustion gangue has features of large porosity, high water absorption, rough surface and so on. Above-mentioned features can be reflected from density, water absorption and crushing index in Table1. Therefore, mix design method of ordinary concrete JGJ 55-2011 [23] cannot be fully applied to design coal gangue concrete, if wanting to meet the requirements of liquidity and concrete strength grade. Additional water and pre-wetting methods, which are needed to introduce into mix design of gangue concrete from lightweight concrete and reduce waterbinder ratio to keep concrete strength grade, simultaneously. According to previous studies and properties of the materials, additional water and pre-wetting time are determined by experiment [24-26]. Finally, the mix proportion of concrete is showed in Table 2.

\subsubsection{Fabrication and curing of test specimens}

In this experiment, according to the four combinations of aggregates, three beams were cast for each group to prevent the error influence. The parameters and details of test beams are showed in Fig.3.

After the workability of fresh concrete was measured, the slumps of four kinds of concrete keep on $200 \mathrm{~mm}$. Then fresh concrete was cast into beam molds and vibrated with vibrating needle simultaneously. All the beams were allowed to stand for $24 \mathrm{~h}$ in laboratory before demolding. Then, molds were stripped and all cubic and prism specimens for mechanical properties of concrete were cured with beams at room temperature and wet condition by watering every day. Sizes of cubic and prism specimens are as following:
$100 \mathrm{~mm} \times 100 \mathrm{~mm} \times 100 \mathrm{~mm}$ for compressive and splitting tensile strengths evaluation;

$100 \mathrm{~mm} \times 100 \mathrm{~mm} \times 300 \mathrm{~mm}$ for axial compressive strength and elastic modulus evaluation.

All specimens were tested at the age of 28 days. The mechanical properties of concrete were tested according to the Standard GB/T50081-2002 [27]. The flexural properties of test beams were tested according to the Standard GB/T50152-2012 [28].

\subsection{Loading device and loading method}

Electro-hydraulic servo universal testing machine was used to load. Loading at two symmetrical points in the $1500 \mathrm{~mm}$ span of beam for eliminating the effect of shear force on the normal section of a flexural member, $500 \mathrm{~mm}$ distributive girder is placed at mid-span of the beam. Reinforcement strain gauge (BX120$5 \mathrm{AA}$ ) was pasted at the middle of longitudinal reinforcement to measure the strain of reinforcement. Beforehand, the middle of the longitudinal reinforcement has been sanded flat. Concrete strain gauge (BX120-80AA) was pasted on the flank of the beam to measure the mid-span strain of concrete (every $25 \mathrm{~mm}$ a strain gauge). The wires of strain gauge connect to the static digital resistance strain tester MYJ-1. Dial indicator is placed on each side of the beam to measure the averaged mid-span deflection. The loading device is showed in Fig.4.

The test adopts the multi-stage loading method according to the code GB/T 50152-2012. Each beam must be pre-loaded until to be stable to load normally. At start of loading, keeping load for a period of time for each $1 \mathrm{kN}$; when the load is going to reach cracking load of member according to pre-computing value, then turning to keep for a period of time for each $0.1 \mathrm{kN}$; after cracking, the loading span is changed to $3 \mathrm{kN}$; when approaching to ultimate bearing capacity of beam, modifying the loading span to $2 \mathrm{kN}$ to observe easily. In the interval of keeping load, 
recording data when numbers of dial indicator and strain tester are stable. At the same time, observing and marking crack of test beam, especially the load of initial crack as cracking load.
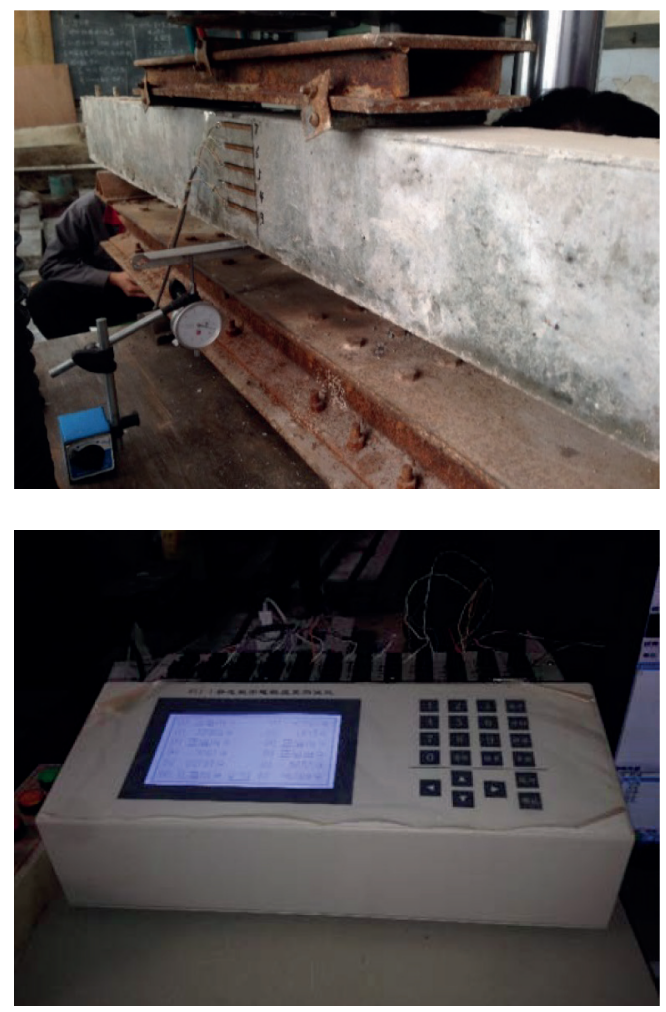

Fig. 4 Loading equipment for test

\section{Results and discussion}

\subsection{Properties of concrete and steel bar}

The properties of concrete and steel bar are showed in Table 3. Different combinations of aggregates lead to different results for the compressive strength and splitting tensile strength of concrete, especially elastic modulus of concrete.

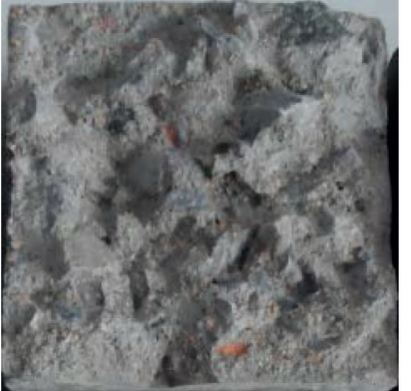

(a) $\mathrm{NC}$

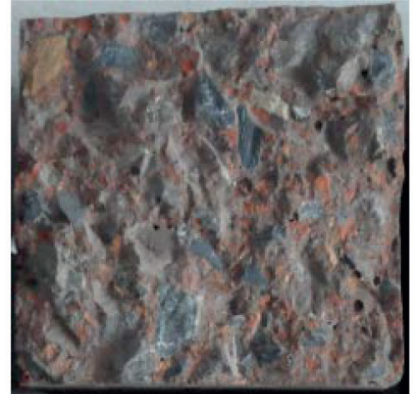

(b) SCG-F

Cubic compressive strength and axial compressive strength are in the range of $35 \sim 40 \mathrm{MPa}$ and $25 \sim 30 \mathrm{MPa}$, which mean that the abovementioned kinds of concretes almost belong the same strength grade. It can be found that the larger the proportion of spontaneous combustion gangue aggregate in concretes, the lower the strength of concretes, shown in the Table 3. Because the porosity of spontaneous combustion gangue is larger than natural stone [29], the strength of spontaneous combustion gangue is lower than natural stone. That is consistent with the above results of crushing index. Therefore, the crack or damage of concrete would cross the spontaneous combustion gangue aggregates directly but bypassed the natural aggregates in the splitting tensile test, which is similar with other studies $[12,16]$. The cross-section morphologies of concrete are showed in Fig. 5.

\subsection{Experimental phenomenon}

Although four kinds of reinforced concrete beams are made of different combinations of aggregates, almost having the similar failure process. In the initial section, load is small and concrete has not cracked, the beam is under the elastic stage. In this stage, deflection of beam linearly increases with load, and strains of concrete and reinforcement are small. Then load increases gradually until the edge of the mid-span tensile zone concrete reach ultimate strain, the concrete cracking. For an instant, partial stress of concrete transfers to reinforcement, resulting in the strain sudden change of it. Concrete and reinforcement start to work together and the strain increases stably. After concrete cracking, the beam enters the plastic state gradually. New cracks increase and extend, which results in deflection of the beam increases heavily with load. Until loading to make the reinforcement to yield, simultaneously, at

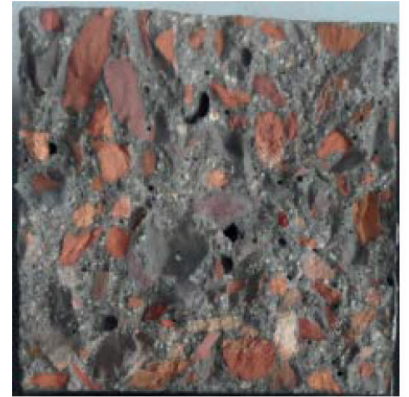

(c) SCG-C

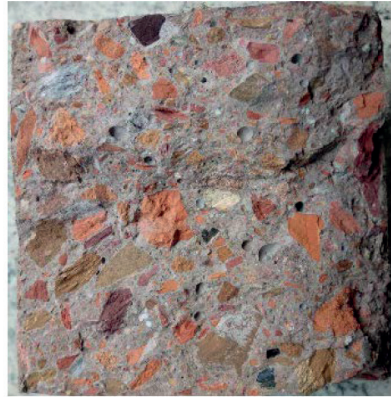

(d) $\mathrm{SCG}-\mathrm{CF}$

Fig. 5 The cross-section morphologies of different concrete specimens

Table 3 Mechanical properties of concrete and reinforcement

\begin{tabular}{|c|c|c|c|c|c|c|c|}
\hline \multirow[b]{2}{*}{ Group } & \multicolumn{4}{|c|}{ Concrete } & \multicolumn{3}{|c|}{ Longitudinal reinforcement } \\
\hline & $\begin{array}{c}\text { Cubic compres- } \\
\text { sive strength } \\
f_{a} / \mathrm{MPa}\end{array}$ & $\begin{array}{l}\text { Axial compressive } \\
\text { strength } \\
f_{c} / \mathrm{MPa}\end{array}$ & $\begin{array}{c}\text { Splitting tensile } \\
\text { strength } \\
f_{t s} / \mathrm{MPa}\end{array}$ & $\begin{array}{c}\text { Elastic modulus } \\
\qquad E_{c} / \mathrm{MPa}\end{array}$ & $\begin{array}{c}\text { Yield strength } \\
f_{y} / \mathrm{MPa}\end{array}$ & $\begin{array}{l}\text { Ultimate strength } \\
\qquad f_{u} / \mathrm{MPa}\end{array}$ & $\begin{array}{c}\text { Elastic modulus } \\
E_{s} / \mathrm{MPa}\end{array}$ \\
\hline $\mathrm{NC}$ & 39.79 & 30.23 & 3.05 & 31100 & \multirow{4}{*}{320.1} & \multirow{4}{*}{432.7} & \multirow{4}{*}{200000} \\
\hline SCG-F & 36.33 & 26.43 & 2.85 & 28900 & & & \\
\hline SCG-C & 39.40 & 29.60 & 2.72 & 21200 & & & \\
\hline SCG-CF & 35.83 & 25.26 & 2.65 & 18800 & & & \\
\hline
\end{tabular}


compressive zone concrete on top of the beam is crushed. That is a symbol of beam failure. From the above description, deformation features and failure models of RSCG beams are similar to reinforced normal concrete (RNC) beams, having elastic, cracking, yield and ultimate stages. Cracks almost distribute in pure bending section. The failure process of RSCG beams is similar with other test results [30, 31]. All test beams belong under-reinforced members. Failure morphologies and crack distributions for all beams are showed in Fig. 6.

\subsubsection{Plane section assumption}

The material of spontaneous combustion gangue is uneven, which leads to the internal structure of SCG concrete having higher inhomogeneity and complexity so that macroscopic mechanical behavior has irregularity and nonlinearity. Aforementioned cases, bringing many difficulties to calculate the mechanical properties of members. Therefore, it is necessary to test and verify the plane section assumption for RSCG beams to simplify calculation, if wanting to apply the formulas in code GB50010-2010 [32].
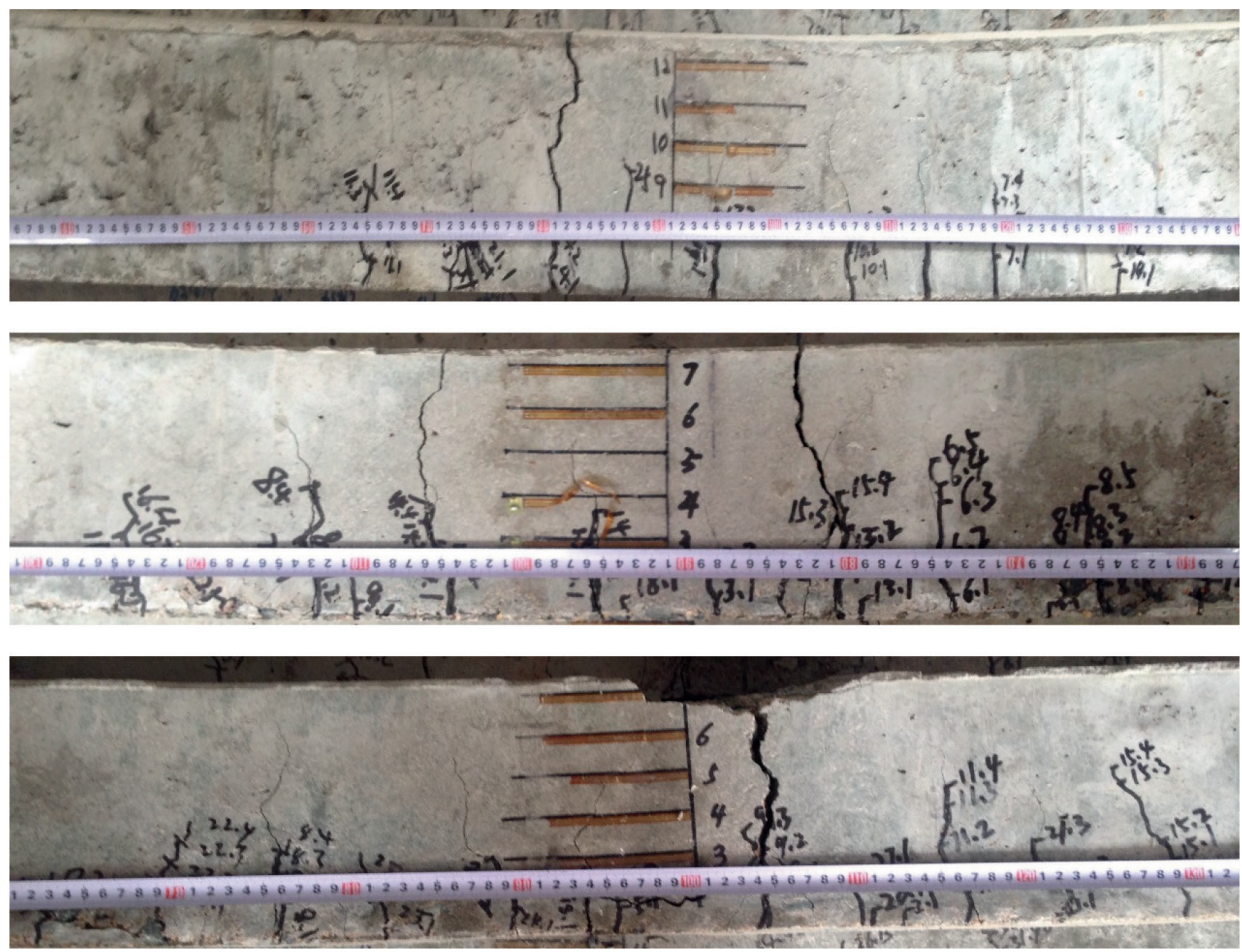

(a) Failure morphology of RNC beams
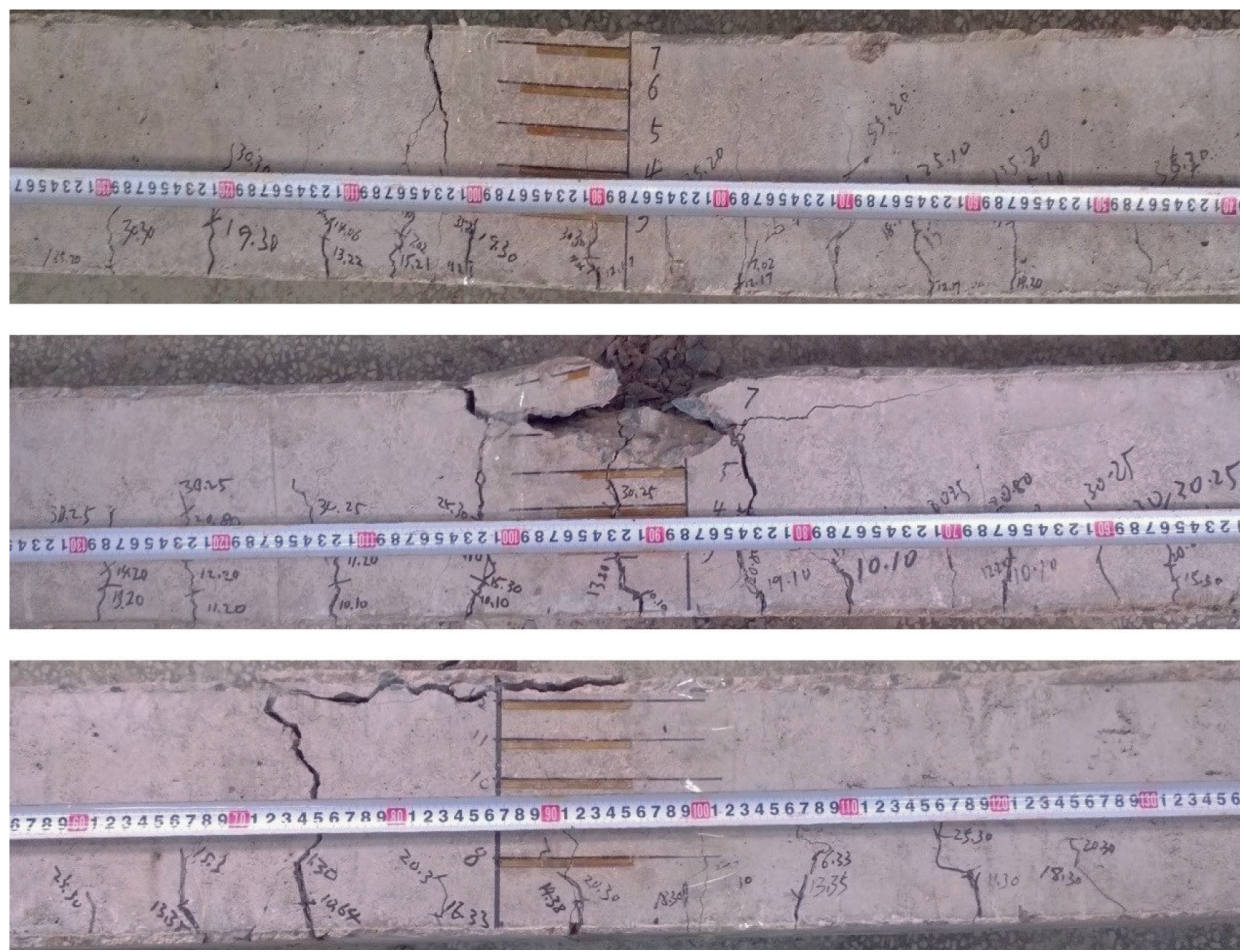

(b) Failure morphology of RSCG-F beams 

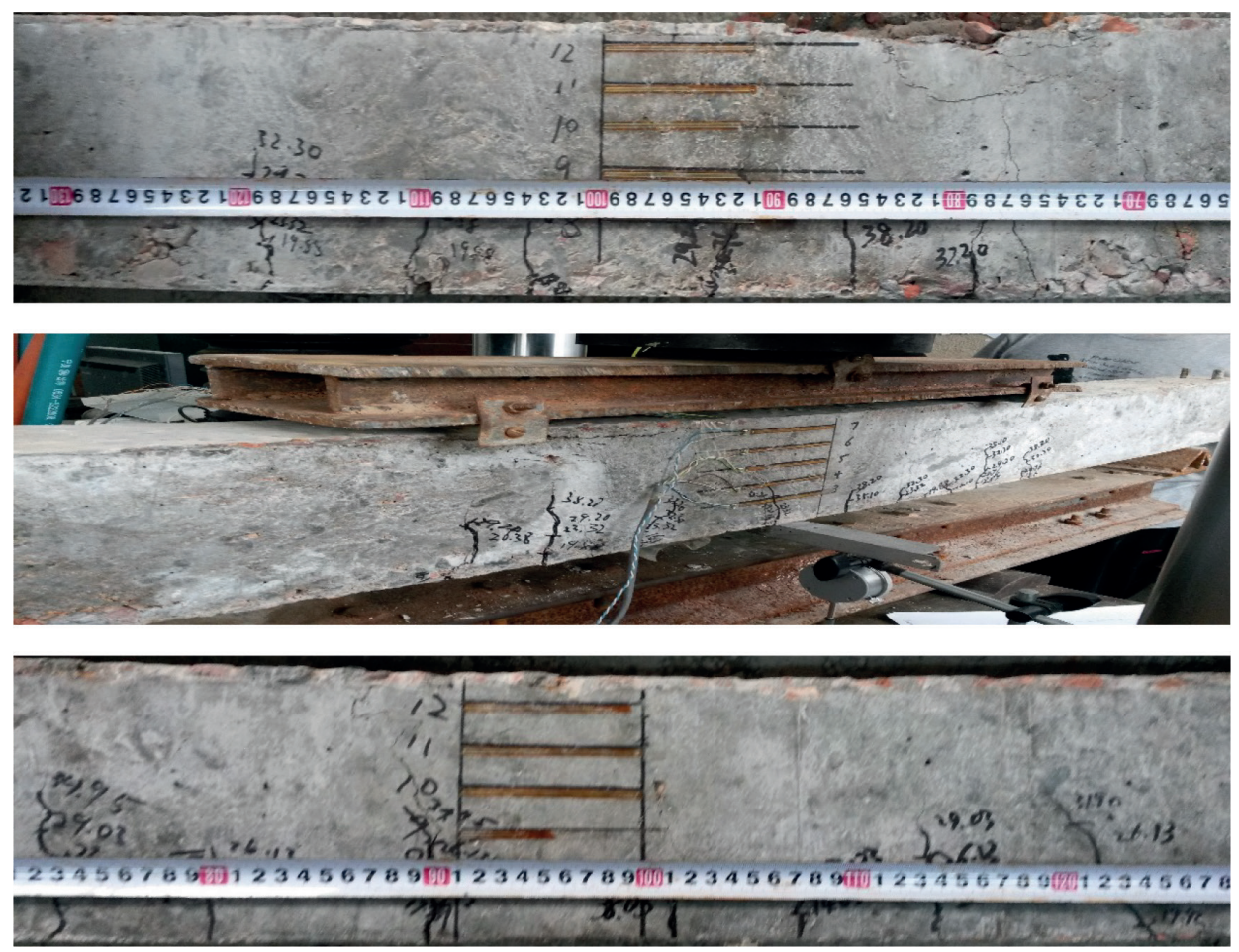

(c) Failure morphology of RSCG-C beams
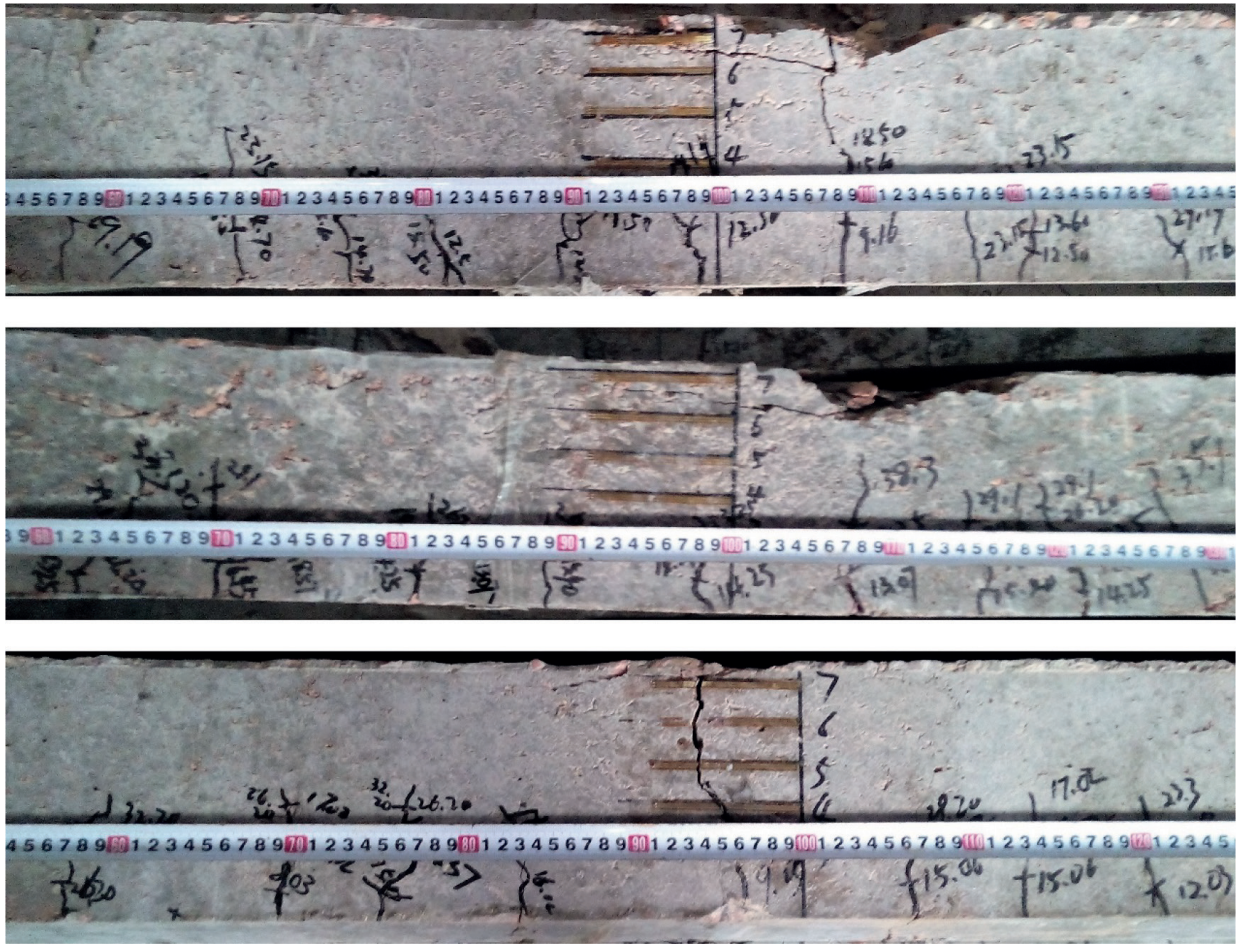

(d) Failure morphology of RSCG-CF beams

Fig. 6 Flexural failure morphology of test beams

Fig.7 (a), (b), (c) and (d) show four kinds of beams, whose strain distribution of reinforcement and concrete along the section height under different load levels in the mid-span section. In the figure, no matter which combinations of aggregates, strain of reinforcement or concrete for each point on the section and distance of the point to the neutral axis are approximately proportional under a certain load. Therefore, RSCG beams conform to the plane section assumption in bending process
[31], however, whose degrees of coincidence are not the same. RSCG-C and RSCG-F beams are clearly more suitable than RSCG-CF beams, but a little less than RNC beams. The reason is the internal structure of SCG concrete has higher inhomogeneity and complexity, especially spontaneous combustion gangue fine and coarse aggregates used in concrete at the same time. The inhomogeneity of aggregate results in the irregularity of concrete and member properties. 

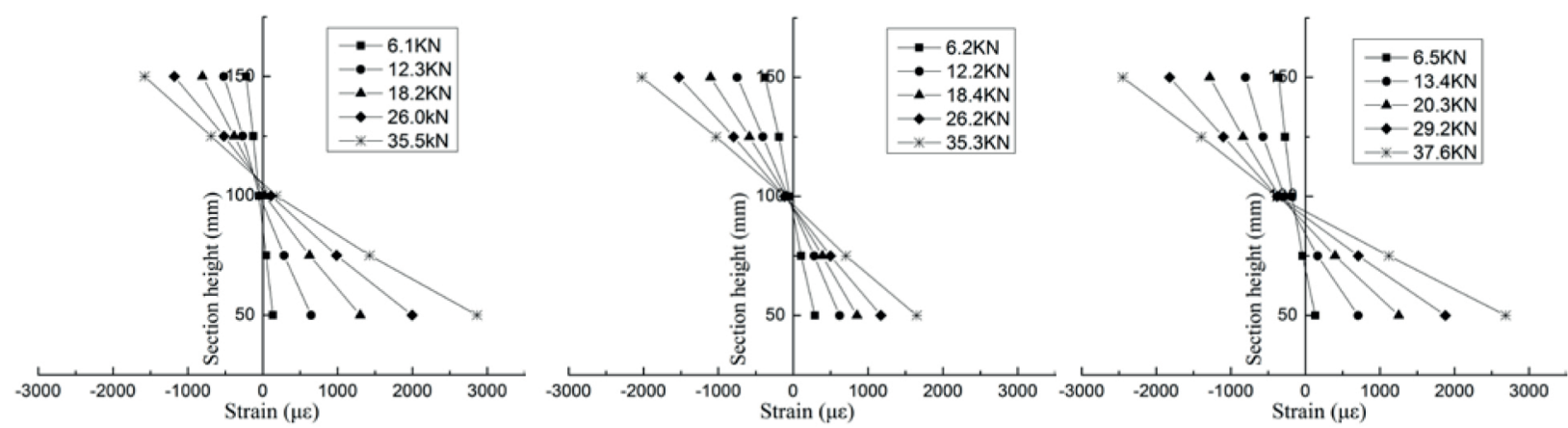

(a) RNC beams
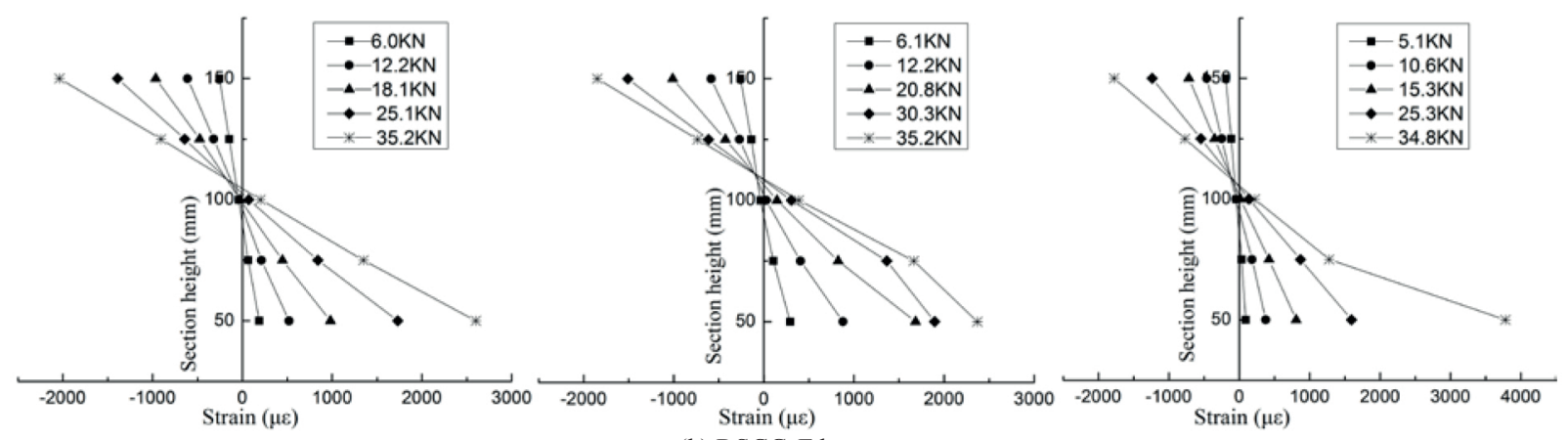

(b) RSCG-F beams
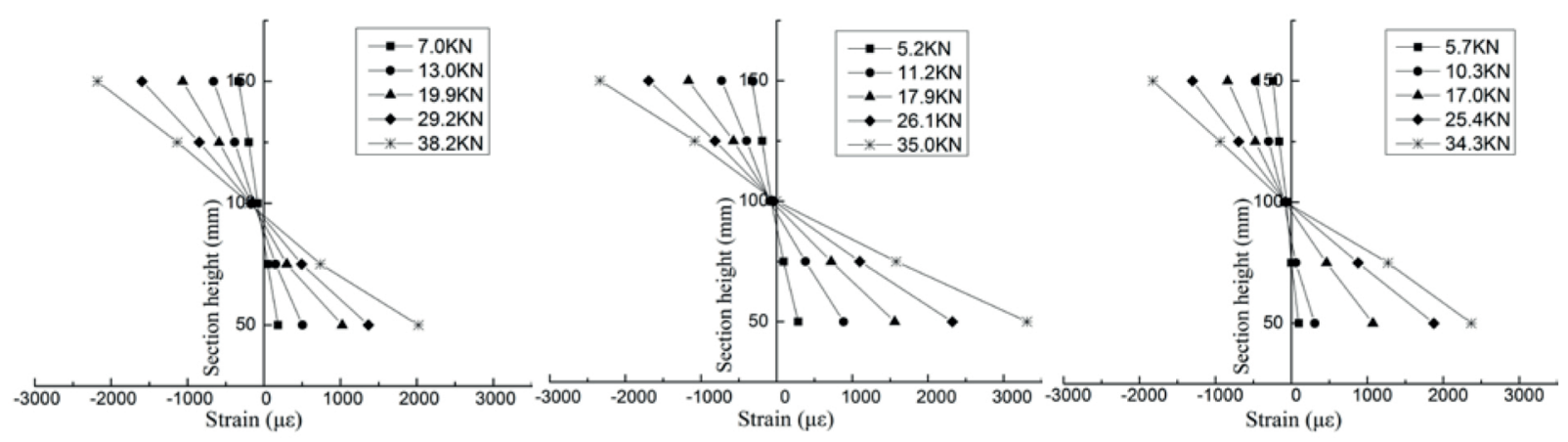

(c) RSCG-C beams
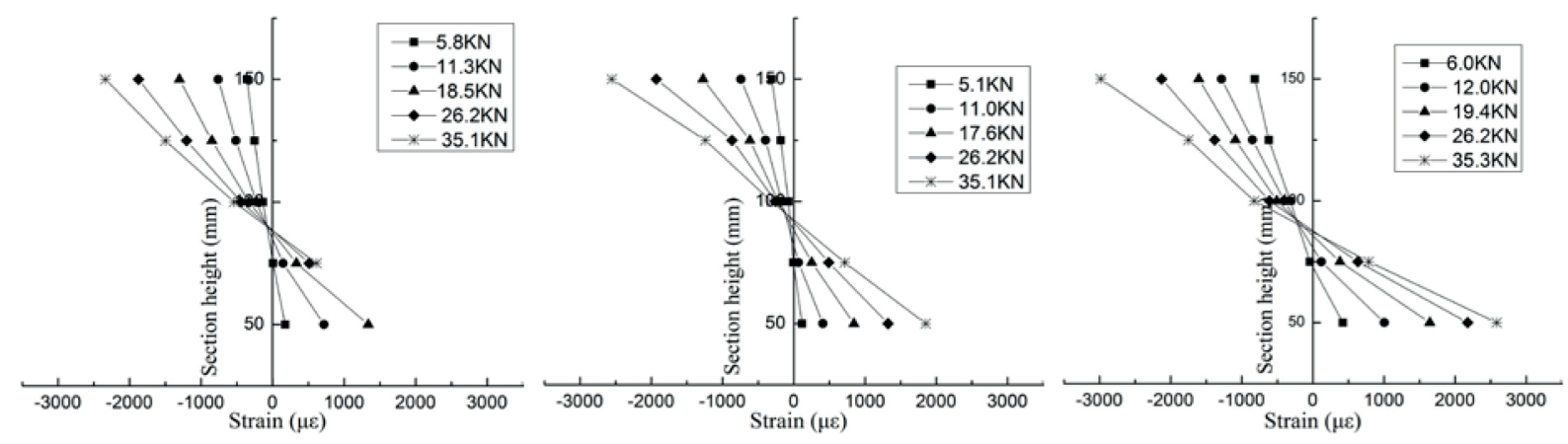

(d) RSCG-CF beams

Fig. 7 The distribution curve of strain for every measuring points along the section height under the action of all levels of load

\subsubsection{Cracking load}

According to the calculating formula of cracking load in present code (GB50010-2010) to calculate the cracking load of test beams, and compared with the measured values. The formula is showed as follows:

Where:

$$
M_{c r}=\gamma f_{t k} W_{0}
$$

$M_{c r}:$ is the cracking moment

$W_{0}$ : is the elastic resistance moment of transformed section to tensile edge $\gamma:$ is the plastic influence coefficient of sectional resistance moment for members, it is 1.55 according to the code and the test member

$f_{t k}$ : is the axis tensile strength standard values of concrete, in the paper it is replaced by conversion value of splitting tensile strength for reflecting the real case of different types of concrete

According to the section size of test beam and the measured data of material can calculate the cracking loads of test beams in the Table 4. 
Table 4 Comparison for measured and calculated values of cracking moment

\begin{tabular}{|c|c|c|c|c|c|c|c|}
\hline \multirow{2}{*}{$\begin{array}{l}\text { No. } \\
\text { RNC-1 }\end{array}$} & \multicolumn{2}{|c|}{$\begin{array}{c}\text { Measured value } \\
M_{c r}^{t} / \mathrm{kN} \cdot \mathrm{m}\end{array}$} & \multirow[t]{2}{*}{$\begin{array}{l}\text { Calculated value } \\
\qquad M_{c r}^{c} / \mathrm{kN} \cdot \mathrm{m}\end{array}$} & \multirow{2}{*}{$\frac{M_{c r}^{t} / M_{c r}^{c}}{1.10}$} & \multirow[t]{2}{*}{ Ave } & \multirow[t]{2}{*}{$\mathrm{S} / \delta$} & \multirow[t]{2}{*}{$\mathrm{Cv} \%$} \\
\hline & 2.38 & & & & & & \\
\hline RNC-2 & 2.40 & 2.39 & 2.16 & 1.11 & 1.11 & 0.01 & 0.6 \\
\hline RNC-3 & 2.40 & & & 1.11 & & & \\
\hline RSCG-F-2 & 2.43 & 2.52 & 2.05 & 1.19 & 1.23 & 0.05 & 4.0 \\
\hline RSCG-F-3 & 2.50 & & & 1.22 & & & \\
\hline RSCG-C-1 & 3.03 & & & 1.45 & & & \\
\hline RSCG-C-2 & 2.95 & 2.95 & 2.09 & 1.41 & 1.41 & 0.04 & 3.0 \\
\hline RSCG-CF-3 & 2.13 & & & 1.01 & & & \\
\hline
\end{tabular}

In Table 4, standard deviation (S) and coefficient variation (Cv) values reflect that discreteness of data is small; the average values (Ave) of $M_{c r}^{t} / M_{c r}^{c}$ for RSCG-F and RSCG-C beams are significantly larger than that of RNC beams and RSCG$\mathrm{CF}$ beams, which are similar to the measured values. Although splitting tensile strengths of SCG-F and SCG-C concrete are smaller than that of NC concrete, the cracking load of beam is not only influenced by one factor but many others (such as bond strength, internal structure of concrete and so on). Different combinations of aggregates lead to different performances of concrete [6]. And coordinative work properties of concrete and reinforcement are also different, because the bonding strength between concrete and reinforcement [33]. Therefore, it can be only sure that the two kinds of beams are good for crack resistance in the bending process. The calculated values of the cracking load for RSCG-F and RSCG-C beams have a large surplus resulting in decreasing economic efficiency of material. It can simply correct by multiplying correction coefficient 1.1 and 1.3, respectively. Nevertheless, further study should be conducted to confirm the underlying reason. The revised average values of $M_{c r}^{t} / M_{c r}^{c}$ for RSCG-F and RSCG-C beams are 1.09 and 1.08 respectively, which are corresponding to 1.11 , the RNC beam. Therefore, overall the present code (GB50010-2010) is suitable for calculation of cracking moment of RSCG beams.

\subsubsection{Ultimate bearing capacity}

According to the calculating formula of ultimate bearing capacity in present code (GB50010-2010) to calculate the ultimate bearing capacity of RSCG beams, and compared with their measured values. The formula is showed as follows:

Where:

$$
M_{u}=f_{y} A_{s}\left(h_{0}-\frac{f_{y} A_{s}}{2 \alpha_{1} f_{c} b}\right)
$$

$f_{y}$ : yield strength of longitudinal reinforcement;

$A_{s}$ : area of longitudinal tension reinforcement;

$f_{c}:$ axial compressive strength of concrete; $\alpha_{1}$ : coefficient of equivalent stress figure, $\alpha_{1}=1.0$ according to the code;

$b$ : width of section for member;

$h_{0}$ : effective height of section for member.

According to the reinforcement figure, data of measured material strength and the formula can calculate ultimate loads of beams in Table 5 .

In Table 5, standard deviation and coefficient variation values are small reflecting that discreteness of data is small; the average values of $M_{u}^{t} / M_{u}^{c}$ or all beams including RNC beams focus on the range from 1.29 to 1.40 . Obviously, measured values are generally larger than calculated values, and they have a big surplus for ultimate bearing capacity of the beam, although the surplus is necessary to be as safety margin in engineering. It may be due to the small test beam section and size inhomogeneity of mould.

The measured value of the ultimate bearing capacity of RSCG-F beam is the biggest in all beams, although the compressive strength of SCG-F concrete is not the biggest. That reflects flexural properties of SCG-F concrete are better than others. Compared with the ultimate bearing capacity of RNC beams, the ultimate bearing capacity of RSCG-C and RSCG-CF beams only reduces by $2.6 \%$ and $5.5 \%$, respectively, only increases by $2 \%$ for RSCG-F beams. Therefore, the present code (GB500102010 ) is suitable for calculation of ultimate bearing capacity of RSCG beams [19, 31], and the results are safe and reliable.

\subsubsection{Deflection under normal service state}

It is likely to lead to excessive deformation for the RSCG members due to the fact that elastic modulus of SCG concrete is smaller than that of normal concrete. If wanting to use it in structural engineering, it is meaningful to study the deflection of RSCG members. Deflection checking for flexural member is under normal service limit state, according to present code (GB50010-2010), the normal section bears roughly 50\% 70\% of the bearing capacity, and the deflection limit value is $l_{0} / 200$ ( $l_{0}$ is calculation span, $l_{0}=1500 \mathrm{~mm}$ in the test). 
Table 5 Comparison for measured and calculated values of ultimate bearing capacity

\begin{tabular}{|c|c|c|c|c|c|c|c|}
\hline No. & $\begin{array}{r}\text { Mea } \\
N\end{array}$ & & $\begin{array}{c}\text { Calculated value } \\
M_{u}^{c} / \mathrm{kN} \cdot \mathrm{m}\end{array}$ & $M_{u}^{t} / M_{u}^{c}$ & Ave & $\mathrm{S} / \delta$ & $\mathrm{Cv} \%$ \\
\hline RNC-1 & 10.63 & & & 1.27 & & & \\
\hline RNC-2 & 11.43 & 11.28 & 8.39 & 1.36 & 1.34 & 0.07 & 4.9 \\
\hline RNC-3 & 11.78 & & & 1.40 & & & \\
\hline RSCG-F-1 & 10.78 & & & 1.31 & & & \\
\hline RSCG-F-2 & 11.73 & 11.51 & 8.26 & 1.42 & 1.40 & 0.08 & 5.6 \\
\hline RSCG-F-3 & 12.03 & & & 1.46 & & & \\
\hline RSCG-C-1 & 11.08 & & & 1.32 & & & \\
\hline RSCG-C-2 & 11.03 & 11.01 & 8.37 & 1.32 & 1.31 & 0.01 & 0.9 \\
\hline RSCG-C-3 & 10.85 & & & 1.30 & & & \\
\hline RSCG-CF-1 & 10.46 & & & 1.27 & & & \\
\hline RSCG-CF-2 & 10.72 & 10.65 & 8.22 & 1.30 & 1.29 & 0.02 & 1.6 \\
\hline RSCG-CF-3 & 10.78 & & & 1.31 & & & \\
\hline
\end{tabular}

Table 6 Comparison for measured and calculated values of deflection

\begin{tabular}{|c|c|c|c|c|c|c|c|}
\hline No. & $\begin{array}{l}\text { Moment } \\
M / \mathrm{kN} \cdot \mathrm{m}\end{array}$ & $\begin{array}{l}\text { Measured value } \\
\qquad f^{t} / \mathrm{mm}\end{array}$ & $\begin{array}{l}\text { Calculated value } \\
\qquad f^{c} / \mathrm{mm}\end{array}$ & $f^{t} / f^{c}$ & Ave & $\mathrm{S} / \delta$ & $\mathrm{Cv} \%$ \\
\hline $\mathrm{RNC}$ & 3.5 & $1.79 / 2.06 / 1.81$ & 1.81 & $0.99 / 1.14 / 1.00$ & 1.04 & 0.08 & 8 \\
\hline RSCG-F & & $1.87 / 2.03 / 1.88$ & 1.91 & $0.98 / 1.06 / 0.98$ & 1.00 & 0.05 & 5 \\
\hline RSCG-C & & $1.87 / 1.89 / 1.93$ & 2.23 & $0.84 / 0.85 / 0.87$ & 0.85 & 0.02 & 2 \\
\hline RSCG-CF & & $2.44 / 2.29 / 2.76$ & 2.39 & $1.02 / 0.96 / 1.15$ & 1.04 & 0.10 & 10 \\
\hline $\mathrm{RNC}$ & 4.5 & $2.44 / 2.77 / 2.49$ & 2.51 & $0.97 / 1.10 / 0.99$ & 1.02 & 0.07 & 7 \\
\hline RSCG-F & & $2.57 / 2.73 / 2.56$ & 2.62 & $0.98 / 1.04 / 0.98$ & 1.00 & 0.03 & 3 \\
\hline RSCG-C & & $2.52 / 2.51 / 2.64$ & 3.03 & $0.83 / 0.83 / 0.87$ & 0.84 & 0.02 & 3 \\
\hline RSCG-CF & & $3.13 / 3.05 / 3.66$ & 3.23 & $0.97 / 0.94 / 1.13$ & 1.01 & 0.10 & 10 \\
\hline $\mathrm{RNC}$ & 5.5 & $3.14 / 3.45 / 3.10$ & 3.20 & $0.98 / 1.08 / 0.97$ & 1.01 & 0.06 & 6 \\
\hline RSCG-F & & $3.28 / 3.41 / 3.21$ & 3.33 & $0.98 / 1.02 / 0.96$ & 0.99 & 0.03 & 3 \\
\hline RSCG-C & & $3.17 / 3.17 / 3.33$ & 3.83 & $0.83 / 0.83 / 0.87$ & 0.84 & 0.02 & 3 \\
\hline RSCG-CF & & $3.89 / 3.82 / 4.34$ & 4.07 & $0.96 / 0.94 / 1.07$ & 0.99 & 0.07 & 7 \\
\hline RNC & 6.5 & $3.80 / 4.11 / 3.70$ & 3.90 & $0.97 / 1.05 / 0.95$ & 0.99 & 0.05 & 5 \\
\hline RSCG-F & & $4.04 / 4.14 / 3.90$ & 4.04 & $1.00 / 1.02 / 0.97$ & 1.00 & 0.03 & 3 \\
\hline RSCG-C & & $3.80 / 3.86 / 4.06$ & 4.63 & $0.82 / 0.83 / 0.88$ & 0.84 & 0.03 & 4 \\
\hline RSCG-CF & & $4.39 / 4.58 / 5.28$ & 4.91 & $0.89 / 0.93 / 1.08$ & 0.97 & 0.09 & 9 \\
\hline $\mathrm{RNC}$ & 7.5 & $4.36 / 4.82 / 4.06$ & 4.59 & $0.95 / 1.05 / 0.88$ & 0.96 & 0.09 & 9 \\
\hline RSCG-F & & $4.81 / 4.88 / 4.60$ & 4.76 & $1.01 / 1.03 / 0.97$ & 1.00 & 0.03 & 3 \\
\hline RSCG-C & & $4.49 / 4.66 / 4.76$ & 5.43 & $0.83 / 0.86 / 0.88$ & 0.86 & 0.03 & 3 \\
\hline RSCG-CF & & $4.88 / 5.37 / 6.11$ & 5.75 & $0.85 / 0.93 / 1.06$ & 0.95 & 0.11 & 11 \\
\hline
\end{tabular}

The deflection checking formula in present code is that:

$$
f=S \frac{M l_{0}^{2}}{E I}=S \varphi l_{0}^{2}
$$

In deflection checking calculation formula, the short-term stiffness formula in present code is that:

Where:

$$
B_{s}=\frac{E_{s} A_{s} h_{0}^{2}}{1.15 \psi+0.2+6 \alpha_{E} \rho}
$$

$S:$ is coefficient associated with load form and supporting conditions

$l_{0}:$ is calculation span of beam $\varphi: \quad$ is sectional curvature means the angle of normal section on unit length

$E I, B_{S}$ : is section bending rigidity of beam

$\psi$ : is strain non-uniform coefficient of longitudinal reinforcement in crack

$\rho:$ is ratio of $A_{S} /\left(b \times h_{0}\right)$

$\alpha_{E}:$ is $E_{S} / E_{C}$

$E_{S}:$ is elastic modulus of reinforcement

$E_{C}:$ is elastic modulus of concrete

According to above-mentioned calculation formula of deflection, comparing measured values with calculated values of deflection under normal service state in Table 6. 
Table 6, standard deviation and coefficient variation values are small reflecting that discreteness of data is small, except for the data of RSCG-CF beams; the averages of $f^{t} / f^{c}$ for all members except for RSCG-C concentrates on 1.00, showing the measured values and calculated values match well. The averages of deflection for RSCG-C beams concentrate on 0.85 , meaning the measured values are smaller than calculated values. It is related to the deformation performance of RSCG$\mathrm{C}$ beams. Generally, deformation performance of member is influenced by raw materials, especially aggregate. Although these properties of SCG concrete are not the best in all kinds, the cracking load in Table 5 and failure morphology in Figure 6 showing crack resistance of RSCG-C beams is better than others. The crack resistant is also related to deformation performance. Also, under the same moment, the deflection of beams increase in order of RNC, RSCG-F, RSCG-C and RSCG-CF, demonstrating adequately aggregate has great influence on deflection or deformation of the beam. In addition, reinforced concrete beam in bending is the process that reinforcement and concrete work harmoniously, the aforementioned case also related to the good harmony between SCG concrete and reinforcement. In a word, deflection checking formula is suitable for RSCG beams under normal service state.

\section{ANSYS finite element simulation}

\subsection{Constitutive models and element types of reinforcement and concrete}

Bending failure of beam is accompanied by nonlinear damage of its structural material, which increases the difficulties of calculation and analysis. Finite element simulation is a simple and effective method to solve above problems. In the paper, nonlinear analysis of RSCG beams is carried out by ANSYS finite element software, then compared with measured results.

An eight-node hexahedron element, Solid 65 which is special for modelling concrete in ANSYS, is used to model concrete in this paper. It can reflect cracking and crushing performances of concrete. Different aggregates affect the flexural properties of beams by affecting the performance of concrete. Thus, we input the measured axial compressive strength, elastic modulus of concrete and other measured results which are indispensable parameters in the structural design to reflect indirectly the influence of spontaneous combustion gangue aggregates on the flexural properties of beams. Link 8 element which is widely used in engineering is used to model reinforcement. The parameters of reinforcement also used the measured results to keep the conditions of test and model consistently.

Deformation features and failure modes of RSCG beams are similar with RNC beams in bending process, and there is no agreed-upon constitutive model of SCG concrete at present. Constitutive relation of concrete is a complicated problem and needs considerable data to support. Thus further research on the point is needed to investigate. In this paper, using the constitutive relation of common concrete replaces all kinds of concrete. According to the Code, the common compression constitutive model of concrete is showed in Fig.8, the tension constitutive model of reinforcement is showed in Fig.9.

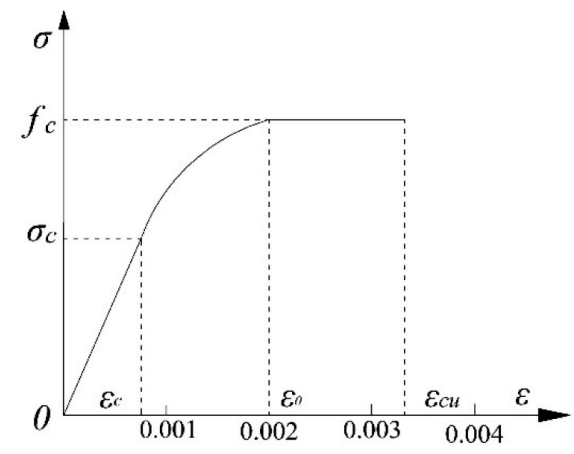

Fig. 8 Concrete stress-stain curve

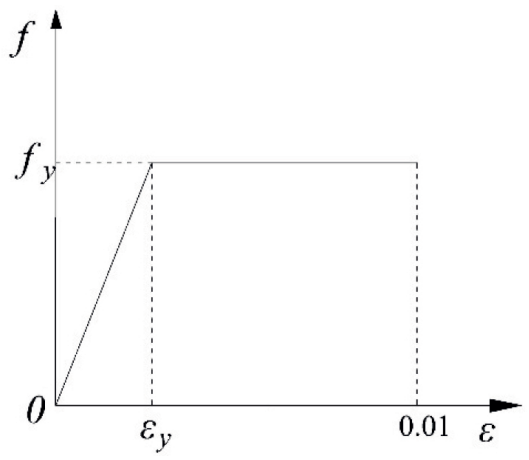

Fig. 9 Reinforcement stress-strain curve

\subsection{Comparison of simulation and test results 4.2.1 Comparison of reinforcement strain curves}

The comparison of measured and simulated load-reinforcement strain curves are showed in Fig.10.

Comparing simulated results with measured results, there are many differences between two curves in details, though the overall trend is comparable. Generally, load-reinforcement strain curves of beam are consisted of three segments, which are straight line segment without cracking, curve segment before reinforcement yielding and after concrete cracking and nearhorizontal segment after reinforcement yielding. However, in the second segment (between two turning points) simulated result is described to a straight line, gap between simulated strain values and measured strain values becomes bigger and bigger with load increase. Because of the unsuitable precondition taking reinforcement as homogeneous material. In all lines, the cracking loads (the first turning point) of the simulation results are smaller than that of measured results, yielding or ultimate loads are also smaller than measured results. It is also connected to the aforementioned reason. Besides, the main reasons for above phenomena are that bond-slip effect between reinforcement and concrete is not considered in the finite element analysis [34]. Meanwhile coordination working capability of reinforcement with concrete and internal structure of concrete is idealized. Differences on ultimate strain values are partly due to limited experimental conditions to obtain limited data. 


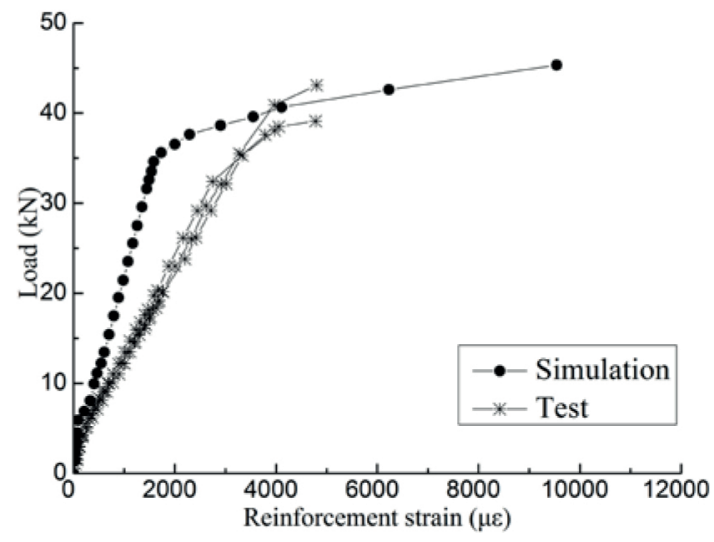

(a) RNC beams

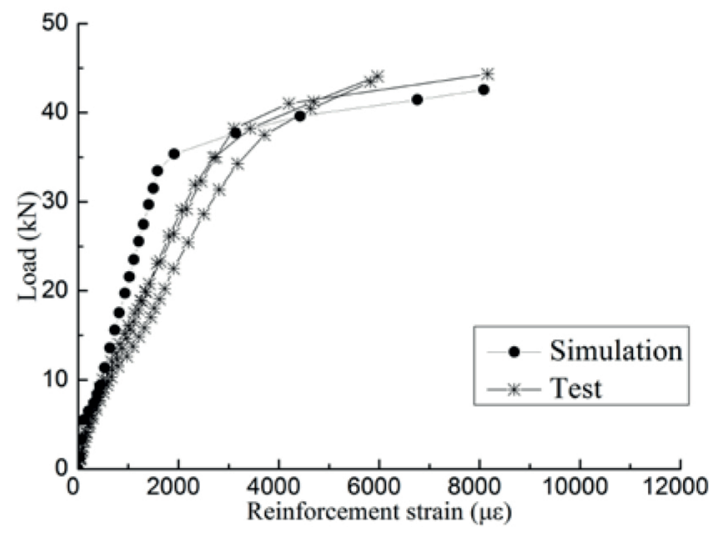

(c) RSCG-C beams

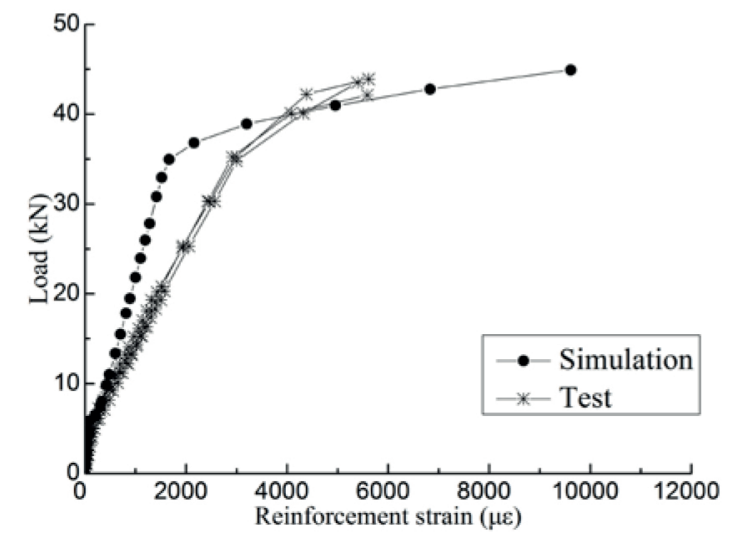

(b) RSCG-F beams

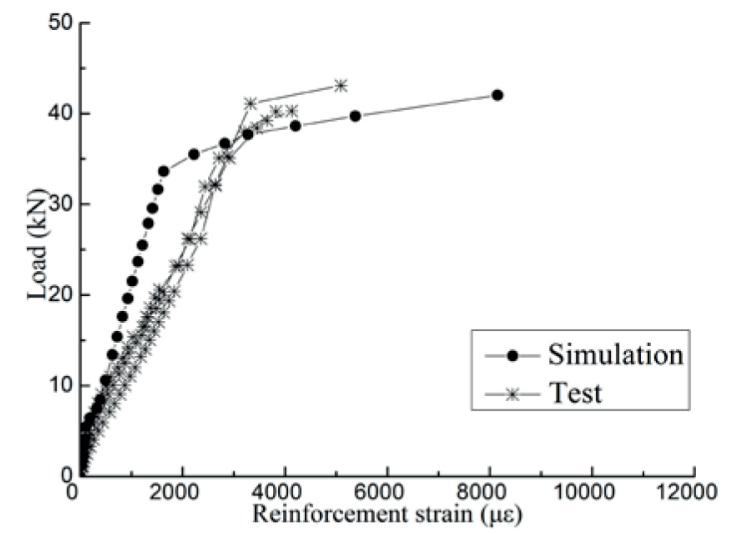

(d) RSCG-CF beams

Fig. 10 Comparison of load-reinforcement strain curves

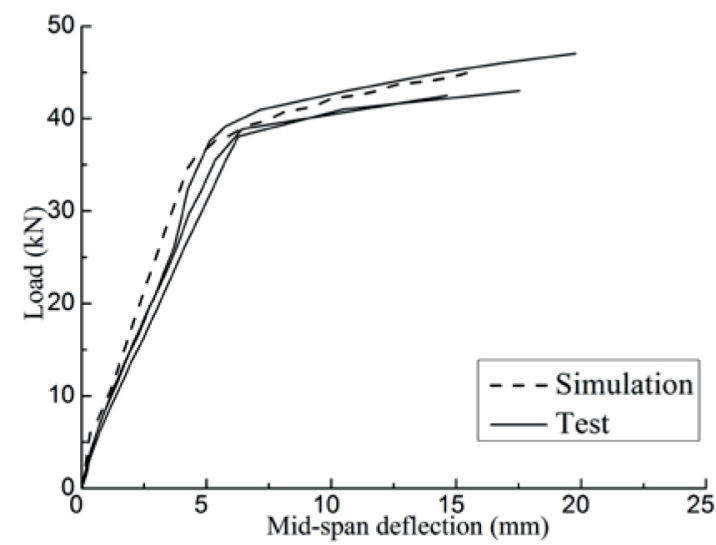

(a) RNC beams

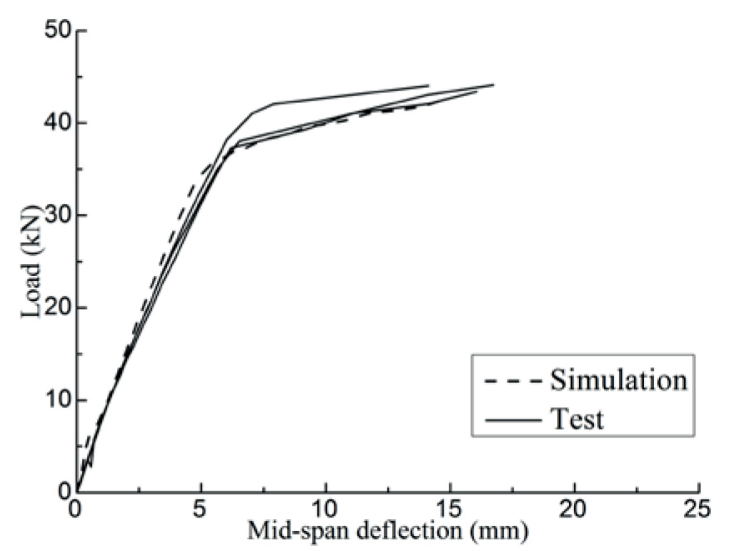

(c) RSCG-C beams

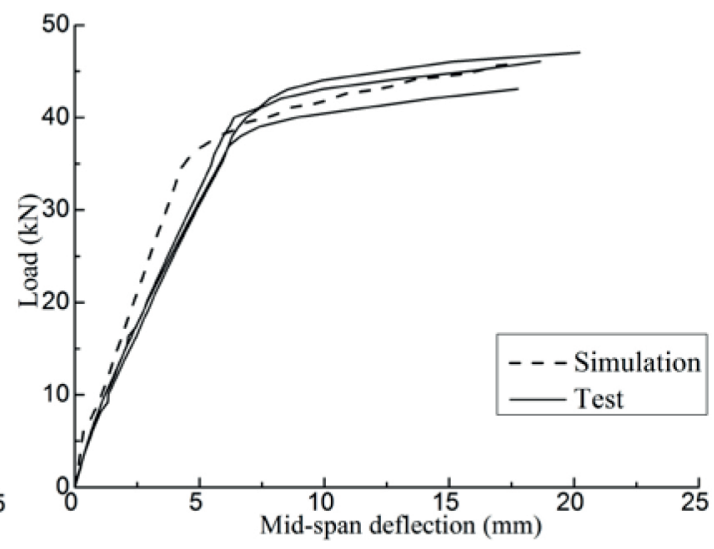

(b) RSCG-F beams

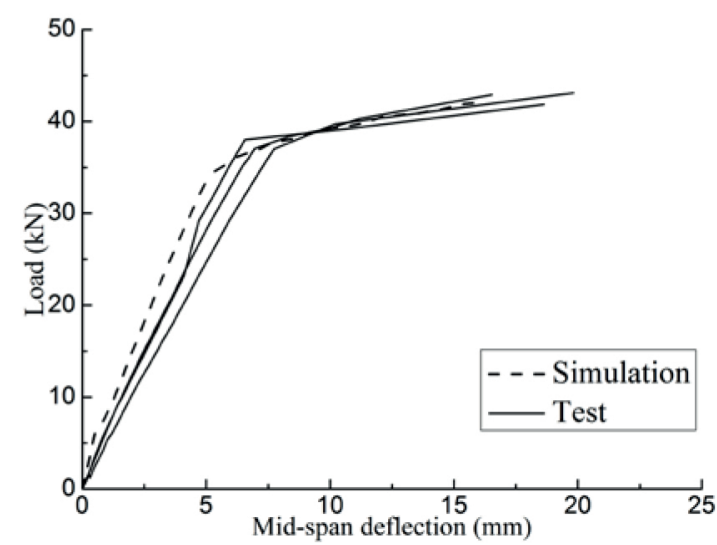

(d) RSCG-CF beams

Fig. 11 Comparison of load-deflection curves 
Table 7 Comparison for measured and simulated values of ultimate bearing capacity

\begin{tabular}{|c|c|c|c|c|}
\hline No. & \multicolumn{2}{|c|}{$\begin{array}{c}\text { Measured value } \\
M_{u}^{t} / \mathrm{kN} \cdot \mathrm{m}\end{array}$} & \multirow[t]{2}{*}{$\begin{array}{c}\text { Simulated value } \\
\qquad M_{u}^{s} / \mathrm{kN} \cdot \mathrm{m}\end{array}$} & \multirow[t]{2}{*}{$M_{u}^{t} / M_{u}^{s}$} \\
\hline RNC-1 & 10.63 & & & \\
\hline RNC-2 & 11.43 & 11.28 & 11.33 & 0.996 \\
\hline RNC-3 & 11.78 & & & \\
\hline RSCG-F-1 & 10.78 & & & \\
\hline RSCG-F-2 & 11.73 & 11.51 & 11.23 & 1.025 \\
\hline RSCG-F-3 & 12.03 & & & \\
\hline RSCG-C-1 & 11.08 & & & \\
\hline RSCG-C-2 & 11.03 & 10.99 & 10.64 & 1.033 \\
\hline RSCG-C-3 & 10.85 & & & \\
\hline RSCG-CF-1 & 10.46 & & & \\
\hline RSCG-CF-2 & 10.72 & 10.65 & 10.51 & 1.013 \\
\hline RSCG-CF-3 & 10.78 & & & \\
\hline
\end{tabular}

\subsubsection{Comparison of mid-span deflection curves}

The comparison of measured and simulated load-deflection curves are showed in Fig. 11.

Fig.11 shows in bending process, simulated and measured load-deflection curves match well, and the curves also have three segments similarly to load-reinforcement strain curves. Especially the near-horizontal segments of curves for beams are almost unanimous and final measured and simulated deflection values are very close. However, under normal service state, measured deflection values are larger than simulated values at the same load, this reflects the stiffness of the test beams decrease faster in experimental process than that in the simulated process. In this condition, cracks increase and extend quickly with load increase leading factual section of the beam to reduce and stiffness decrease [35]. Late deformation ability of RSCG beams is good as shown in Fig.11.

\subsubsection{Comparison of ultimate bearing capacity}

The comparison of measured and simulated ultimate bearing capacity is showed in Table 7.

Table 7 shows the measured and simulated values of ultimate bearing capacity match very well, and the ratio of $M_{u}^{t} / M_{u}^{s}$ focus on the range (0.996-1.033). This is a further indication that the material definition, constraint conditions and loading method match well with experimental situations.

In conclusion, it is reliable to predict the ultimate bearing capacity of RSCG beams by ANSYS finite element simulation.

\section{Conclusions}

Through above experiments and analysis for reinforced concrete beams made of four different aggregate combinations. The following conclusions can be drawn that:

(1) The bending features of RSCG beams are similar with RNC beams, also having elastic, cracking, yield and ultimate stages. RSCG beams have basically the same flexural mechanism and failure process with RNC beams. RSCG beams meet plane section assumption in bending process.
(2) The calculated method and theory of cracking load in present code are also suitable to RSCG beams. Cracking loads of RSCG-CF and RNC beams have proper surplus, but RSCG$\mathrm{F}$ and RSCG-C beams have a big surplus, this paper simply introduces parameters 1.1 and 1.3 to correct calculation formula, respectively. Further study should be conducted to confirm the underlying reason.

(3) Under the same conditions, ultimate bearing capacity of all beams is safe, especially RSCG-F beams, shown from the ratio of measured values to calculated values.

(4) Under normal service state, the measured mid-span deflection values of all beams match well with calculated mid-span deflection values, except for RSCG-C beams. The method and theory in present code are applicable to calculate the deflection of RSCG beams in bending process, and RSCG$\mathrm{C}$ beams are safer than others. Thus it is feasible to use spontaneous combustion gangue aggregate in reinforced concrete structures under the proper design as well as within the proper limit of application.

(5) Based on the test data, the bending processes of RSCG beams are also analyzed by ANSYS finite element software. The results show that simulated load-deflection curves and ultimate bearing capacity of all beams match well with measured results. Although the load-reinforcement strain curves of two results have a comparative trend, they have many differences. Consequently, RSCG bending members can be analyzed by finite element model in engineering, especially predict ultimate bearing capacity of beam. But it is necessary to check by experiments, if wanting to know the bending process detailedly.

\section{Acknowledgments}

This work was sponsored by the National Natural Science Foundation of China (U1261122, 51578108, 51278086), Special Fund for Scientific Research in the Public Interest by Ministry of Water Resource of the People's Republic of China (201501003) and the limited company of Shenhua Group. 


\section{References}

[1] Li, Z., Zhou, Q. "Tailing and gangue: the prosperity resources be recycled”. Engineering Science, 6(9), pp. 20-22. 2004. https://doi. org/10.3969/j.issn.1009-1742.2004.09.004

[2] Chen, W., Yang, J., Zhan, L. "The Technology of Reclamation of Solid from Coal". Chemical Industry Press, Beijing, China, pp. 54-56. 2011. (in Chinese)

[3] Qing, F. "Coal gangue treatment abroad and its economic benefits". Hebei Coal, 4, pp. 53-55. 1990. (in Chinese)

[4] Ma, C. "The test of natural coal spoil material characteristics". Journal of Taiyuan University of Technology, 34(2), pp. 154-157. 2003. (in Chinese) https://doi.org/10.16355/j.cnki.issn1007-9432tyut.2003.02.015

[5] Yang, Z.-Q., Qian, J.-S., Tang, Z.-Q., Liang, T.-Y. "Effect of aggregate-matrix harmony on the strength of concrete". Materials Science and Technology, 15(1), pp. 72-1240. 2007.

[6] Chen, W. "Feasibility study of coal gangue as aggregate of cement concrete". Master's Degree of Beijing University of Technology. 2010. (in Chinese with English summary)

[7] Zhang, J., Chen, W., Jin, S., Chen, C., Yang, R. "Investigation on durability of coal gangue aggregate concrete". Journal of Beijing University of Technology, 37(1), pp. 116-125. 2011. (in Chinesewith English summary)

[8] Duan, X., Xia, J., Yang, J. "Influence of coal gangue fine aggregate on microstructure of cement mortar and its action mechanism". Journal of Building Materials, 17(4), pp. 700-705. 2014. (in Chinese) https://doi. org/10.3969/j.issn.1007-9629.2014.04.025

[9] Li Y, Xing Y, Zhang X and et al. "Experimental study on the durability of the concrete with coal gangue aggregate". Journal of China Coal Society, 38(7), pp. 1215-1219. 2013. (in Chinese) https://doi.org/10.13225/j. cnki.jccs.2013.07.007

[10] Li, H. "Comprehensive Utilization of Coal Gangue". Chemical Industry Press, Beijing, China. 2010.

[11] Salguero, F., Grande, J. A., Valente, T., Garrido, R., de la Torre, M. L., Fortes, J. C., Sánchez, A. "Recycling of manganese gangue materials from waste-dumps in the Iberian pyrite belt-application as filler for concrete production". Construction and Building Materials, 54, pp. 363368. 2014. https://doi.org/10.1016/j.conbuildmat.2013.12.082

[12] Zhang, J., Sun, H., Wan, J., Yi, Z. "Study on microstructure and mechanical property of interfacial transition zone between limestone aggregate and Sialite paste". Construction and Building Material, 23(11), pp. 3393-3397. 2009. https://doi.org/10.1016/j.conbuildmat.2009.06.037

[13] Duan, X. "Study on the Micro-Structure and physical-mechanical performance of concrete with coal gangue as aggregate". Doctoral Dissertation of China University of Mining and Technology. 2014.

[14] Zhou M, Zhu H and Wang Z. "Study of spontaneous combustion coal gangue steel fiber reinforced lightweight aggregate concrete". Journal of Building Materials, 131(6), pp. 715-720. 2008. (in Chinese) https://doi. org/10.3969/j.issn.1007-9629.2008.06.017

[15] Zhang, J-X., Chen, W.-L., Yang, R.-J. "Experimental study on basic properties of coal gangue aggregate". Journal of Building Materials, 13(6), pp. 739-743. 2010. (in Chinese) https://doi.org/10.3969/j.issn.10079629.2010.06.007

[16] Zhou, M., Tian, S., Guo, T. "Experiment research on the concrete using spontaneous combustion gangue as full active material". Bulletin of the Chinese Ceramic Society, 30(5), pp. 1221-1226. 2011. (in Chinese) https://doi.org/10.16552/j.cnki.issn1001-1625.2011.05.016

[17] You, S., Shen, X. "Durability of structure of concrete with spontaneous-ignition gangue lightweight aggregates". Fly Ash, 17(2), pp. 3942. 2005. (in Chinese).

[18] Chen, Y., Sun, Q. "Study on the spontaneous combustion coal gangue concrete". Concrete, 10, pp. 63-65. 2014. (in Chinese) https://doi. org/10.3969/j.issn.1002-3550.2014.10.017
[19] Chen, B. "Bearing capacity of coal gangue-concrete bending member". Journal of Huaqiao University (Natural Science), 16(2), pp. 168-172. 1995. (in Chinese).

[20] Li, G., Ma, L., Chen, Y. "Analysis of the whole process of gangue concrete filled steel tubular beam under loading". In: 8th International Conference on Steel-concrete Composite and Hybrid Structures (ASCCS). Steel Construction, Harbin, China, pp. 355-360. 2006.

[21] Li, G., Lang, Y., Zhao, X. "Behavior of joint of gangue concrete-filled steel tubular column with reinforced gangue concrete beam under low-cyclic loads". In: Proceedings of International Conference on Earthquake Engineering-the First Anniversary of Wenchuan Earthquake, Southwest Jiaotong University Press, Chengdu, China, pp. 105109. 2009.

[22] Li, G., Sun, W., Leon Roberto, T. "Hysteretic performance of steel beam to gangue CFST column connections with ring stiffeners under low reversed cyclic loading". Advanced Steel Construction, 7(2), pp. 173-181. 2011. https://doi.org/10.18057/IJASC.2011.7.2.4

[23] HUDC Housing and Urban-rural Development of China. JGJ 55-2011: Specification for Mix Property Design of Ordinary Concrete. Housing and Urban-rural Development of China, Beijing, China. 2011.

[24] Zhang, B., Kong, L., Yuan, J., Ge, Y. "Effect of prewetting degree of lightweight aggregate on mechanical properties of specified density concrete". Concrete, 10, pp. 24-30. 2006. (in Chinese) https://doi. org/10.3969/j.issn.1002-3550.2006.10.008

[25] Zhou, M., Pu, B., Xu, M. "Effect of additional and prewet time on performance of spontaneous combustion gangue sand lightweight concrete". Bulletin of the Chinese Ceramic Society, 32(12), pp. 1-6. 2013. (in Chinese) https://doi.org/10.16552/j.cnki.issn1001-1625.2013.12.006

[26] Zhou M, Li, G., Zhang, Q., Cui, H. "Study on the application of spontaneous combustion coal gangue aggregate in ready-mixed concrete". Journal of Building Materials, 18(5), pp. 830-835. 2015. (in Chinese) https://doi.org/10.3969/j.issn.1007-9629.2015.05.020

[27] CMC (Construction Ministry of China). GB/T50081-2002: Standard for Test Method of Mechanical Properties on Ordinary Concrete. Construction Ministry of China, Beijing, China. 2002.

[28] HUDC (Housing and Urban-rural Development of China). GB/T 501522012: Standard for Test Method of Concrete Structures.Housing and Urban-rural Development of China, Beijing, China. 2012.

[29] Mu, S. "Study on high fluidity spontaneous combustion coal gangue full-lightweight concrete". Master's Degree Thesis of Liaoning Technical University. 2012.

[30] Yan, L. "Seismic experimental study of the building block for coal gangue concrete". Master's Degree Thesis of Tianjin University. 2012.

[31] Wu, B., Wang, J. "Experimental study of reinforced coal gangue concrete beams under static loading". Journal of Anhui Institute of Architecture (Natural Science), 20(1), pp. 60-65. 2012. (in Chinese)

[32] CMC (Construction Ministry of China). GB 50010-2010: Code for Design of Concrete Structures. Construction Ministry of China, Beijing, China. 2011.

[33] Ma, F. "Behavior and application prospect of coal gangue concrete structure”. Shanxi Architecture, 29(1), pp. 27-28, 2003. (in Chinese)

[34] Sun, M. "Experimental study and finite element analysis on the bond stress slip relationship of RC structure". Master's Degree Thesis of Zhejiang University. 2015.

[35] Song, X. "Experimental research on recycled concrete beams bending performance”. Master's Degree Thesis of Zhengzhou University. 2006. 